\title{
Width-Modulated Microfluidic Columns for Gas Separations
}

Hamza Shakeel, Dong Wang, James. R. Heflin, and Masoud Agah, Senior Member, IEEE

\begin{abstract}
Microgas chromatography separation columns typically employ channels with fixed cross sections. In this paper, we demonstrate a new class of unidirectional microfabricated width-modulated columns $(\mu \mathrm{WMC})$ that afford improved chromatographic efficiency, resolution, and retention times compared with corresponding constant width $(120 \mu \mathrm{m})$ bidirectional columns. Two new $\mu$ WMCs architectures are introduced: 1) a linearly variable column (LVC) and 2) a stepgradient column (SGC). The width of a 1-m long, 250- $\mu$ m-deep LVC is gradually reduced from 120 to $20 \mu \mathrm{m}$ at $1 \mu \mathrm{m} / \mathrm{cm}$. While that of a 1-m-long SGC is modulated in five steps $(120,95,70$, 45 , and $20 \mu \mathrm{m}$ ) each with a length of $20 \mathrm{~cm}$. The effect of inlet selection (120 or $20 \mu \mathrm{m})$ on chromatographic performance is also evaluated. Moreover, with our improved fabrication process, multiple serially connected devices are simultaneously coated for the first time with highly stable silica nanoparticles utilizing layer-by-layer technique enabling constant film thickness.
\end{abstract}

Index Terms-Micro gas chromatography, width-modulated micro columns, silica nanoparticles.

\section{INTRODUCTION}

G AS chromatography (GC) is a versatile and widely acceptable chemical analysis technique based on the distribution of a sample between two immiscible phases (a stationary phase and a mobile phase). A typical GC system consists of a carrier gas (mobile phase), an injector, a separation column (with a fixed cross-sectional area) coated with a thin film (stationary phase), a detector, and a data acquisition system. Figure 1 shows the schematic representation of a bench-top GC system. The sample mixture is first introduced as a concentrated plug into the instrument (GC oven) through a heated injection port and carried through the separation column by an inert carrier gas (mobile phase). Afterwards the components of a mixture are physically separated from one another by the separation column based on their interaction with the stationary phase bed. Next, the separated gas mixture along with a carrier gas enters the detector; that converts the

Manuscript received March 28, 2014; revised May 17, 2014; accepted May 20, 2014. Date of publication May 22, 2014; date of current version August 18, 2014. This work was supported by the NSF Office of the Director under Award ECCS-1002279. The Associate Editor coordinating the review process was Prof. Srinivas Tadigadapa.

H. Shakeel and M. Agah are with the Virginia Tech Microelectromechanical Systems Laboratory, Bradley Department of Electrical and Computer Engineering, Virginia Polytechnic Institute and State University, Blacksburg, VA 24061-0111 USA (e-mail: hshakeel@vt.edu; agah@vt.edu).

D. Wang and J. R. Heflin are with the Department of Physics, Virginia Polytechnic Institute and State University, Blacksburg, VA 24061-0111 USA (e-mail: wdong@vt.edu; rheflin@vt.edu).

Color versions of one or more of the figures in this paper are available online at http://ieeexplore.iee.org.

Digital Object Identifier 10.1109/JSEN.2014.2326593

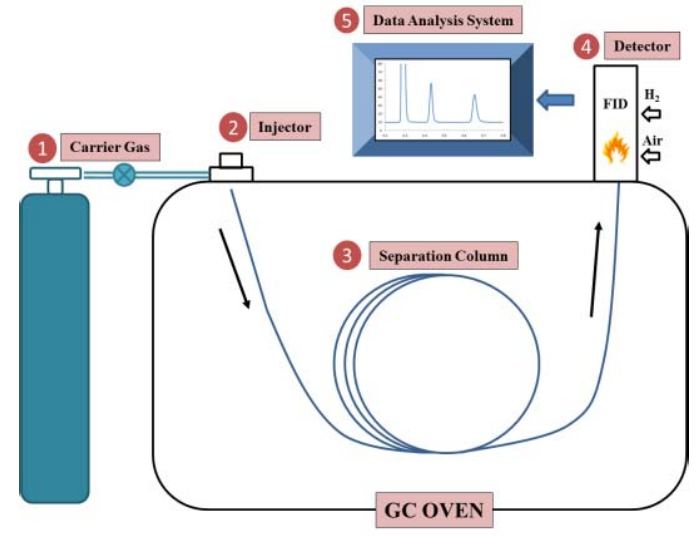

Fig. 1. Schematic representation of a bench-top gas chromatograph.

chemical signal to an equivalent analog electrical output for measurements. Subsequently the data acquisition system plots the detector response against the time axis on a graph known as a chromatograph. For a well-separated gas mixture each peak on the chromatograph corresponds to an individual constituent of a mixture.

Due to its reliability and low detection limits, GC has established itself in a multitude of fields (petrochemical industry, pharmaceutical sciences, biological sciences, and forensic analysis) for the identification and quantification of mixture components. Despite these well-defined advantages, conventional GC systems are large, expensive, power hungry and illsuited for field applications. The emergence of microelectromechanical systems (MEMS) along with nanotechnology has enabled the miniaturization and performance enhancement of key GC components [1]-[11].

Separation columns, being an integral part of the system, have also attracted significant attention and a number of prototype micro-GC $(\mu \mathrm{GC})$ systems have also utilized silicon micromachined columns [12]-[14]. Typical MEMSbased separation columns have been designed with a fixed cross-sectional area, having either rectangular [15] or circular channel profiles [16], and are normally coated with polydimethylsiloxane based stationary phases [17]. Advancements in silicon micromachining techniques have enabled the introduction of novel column architectures in the last decade. Partially buried columns were introduced by A. Radadia et al. [18] to enable the uniform deposition of polymer based phases. Similarly, Agah et al. [19] introduced columns with suspended microchannels using low-mass oxynitride films to achieve high-efficiency separations. Moreover, in order to enhance 
key performance parameters like sample capacity, analysis time and separation efficiency, our group also previously introduced MEMS based narrow-width multicapillary [20] and semipacked columns having embedded micropillars [21], [22]. Additionally, innovative research work on deposition of nontraditional adsorbent based stationary phase coatings for rectangular microchannels has also been performed. This includes the integration of carbon nanotubes [23], self-assembled thiol monolayers [20], [24], silica nanoparticles [25] and MEMS compatible sputtered silica [26] thin-films inside the anisotropically etched channels.

As early as 1962, Purnell [27] suggested that gradual reduction in solvent-adsorbent interaction along the length of the column could effectively provide similar capabilities (shorter analysis times and improved sensitivity) as afforded by the programmed temperature or the programmed flow modes. This interaction could be minimized gradually by reducing either the stationary phase thickness or the column width. Although, effects of gradual reduction in stationary phase thickness have been theoretically studied and experimentally demonstrated [28], the effect of channel modulation on the separation process could not be materialized earlier due to fabrication difficulties. In this article, by employing a single lithography mask and a simple micromachining process, modulation in column width is achieved.

\section{Theoretical Discussion}

The efficiency of a chromatographic column is expressed in terms of either a theoretical plate number $(\mathrm{N})$ or heightequivalent-to-a-theoretical-plate $(\mathrm{HETP}=\mathrm{L} / \mathrm{N})$. As a general rule a high efficiency column has higher theoretical plates and less band-broadening (small HETP term). HETP could be further expanded to include the effects of diffusion in the mobile phase and mass-transfer in mobile and stationary phases. For the rectangular channels HETP is given by

$$
\begin{aligned}
& \text { HETP }=\frac{2 D_{g}}{\bar{u}} f_{1} f_{2} \\
& +\left[\frac{\left(1+9 k+25.5 k^{2}\right)}{105(k+1)^{2}} \frac{\mathrm{w}^{2}}{D_{g}} \frac{f_{1}}{f_{2}}+\frac{2}{3} \frac{k}{(k+1)^{2}} \frac{(\mathrm{w}+\mathrm{h})^{2} \mathrm{~d}_{\mathrm{f}}^{2}}{\mathrm{D}_{\mathrm{s}} \mathrm{h}^{2}}\right] \overline{\mathrm{u}}
\end{aligned}
$$

where $D_{g}$ and $D_{s}$ are the binary diffusion coefficients in the mobile and stationary phase, $\bar{u}$ stands for the linear gas velocity, $f_{1}$ and $f_{2}$ are the Giddings-Golay and Martin-James gas compression coefficients respectively, $\mathrm{k}$ is the retention factor that is characteristic of a stationary phase, w stands for channel width and $h$ for the channel height/depth [29].

To simplify the analysis, we ignore diffusion in the mobile phase (1st term) and also assume a very thin stationary phase film (small $\mathrm{d}_{\mathrm{f}}$-term) therefore, we can neglect the contribution of band-broadening due to diffusion in the stationary phase (3rd term) in equation (1). The HETP becomes directly proportional to the square of column width.

$$
\text { HETP } \propto w^{2}
$$

It is clear from equation (2) that columns with smaller width will provide efficient separations and column-width is one of

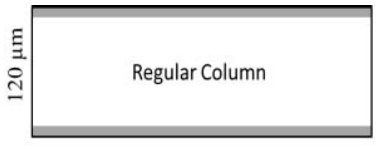

(a)

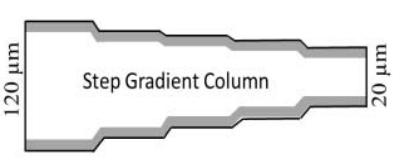

(c)

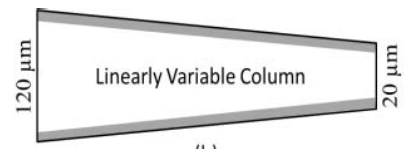

(b)

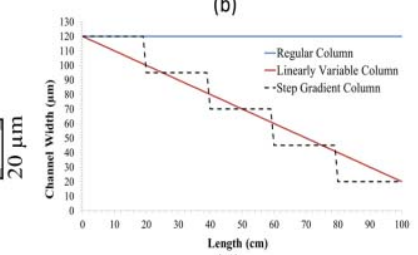

(d)
Fig. 2. Channel profiles of $1 \mathrm{~m}$ long (a) regular, (b) linearly variable and (c) step gradient columns. (d) Shows the plot for channel width versus channel length.

the critical design parameters. Moreover, if the width of a column is gradually reduced along the length, then HETP will also decrease locally and effectively the overall HETP values will reduce. Therefore, in this article the modulation in width of the column is carried out and two new microfabricated width modulated column ( $\mu \mathrm{WMC})$ are introduced for the first time (Fig. 2). The width of the linearly-variable-column (LVC) is modulated from $120 \mu \mathrm{m}$ to $20 \mu \mathrm{m}$ at $1 \mu \mathrm{m} / \mathrm{cm}$ (Fig. 2b), and the step-gradient column (SGC) is modulated in 5 steps (120 $\mu \mathrm{m}, 95 \mu \mathrm{m}, 70 \mu \mathrm{m}, 45 \mu \mathrm{m}$ and $20 \mu \mathrm{m})$ each with $20 \mathrm{~cm}$ length (Fig. 2c). Moreover, for the step gradient column, the interconnections between the steps are gradually varied over the length of $700 \mu \mathrm{m}$. The separation capabilities of newly developed $\mu \mathrm{WMCs}$ are realized by utilizing our recently developed layer-by-layer ( $\mathrm{LbL}$ ) technique to get a highlystable silica nanoparticle (SNP) stationary phase. Additionally, by shifting the stationary phase deposition step to occur after anodic bonding, multiple serially connected columns are coated simultaneously providing high-throughput. The detailed fabrication process and chromatographic performance of our proposed $\mu \mathrm{WMCs}$ with SNPs coating is explained below.

\section{Column Development}

\section{A. Fabrication}

Fig. 3 shows the single mask MEMS fabrication process for SNP coated columns on 4 inch, $500 \mu \mathrm{m}$ thick single-side polished silicon and double side-polished Borofloat wafers. $1 \mathrm{~m}$-long, $250 \mu \mathrm{m}$-deep $\mu \mathrm{WMCs}$ and regular columns are realized using photolithography, deep reactive ion etching (DRIE) and anodic bonding. The fabrication of devices starts with the standard RCA cleaning and the priming of a silicon wafer. Afterwards, an $8 \mu \mathrm{m}$ thick AZ9260 photoresist is patterned using a mask aligner followed by development in AZ 400K (Fig. 3a). Next, the patterned wafer is hard baked for 4 minutes at $110{ }^{\circ} \mathrm{C}$ and then etched anisotropically using DRIE to get the desired channel dimensions. Following this, the etched silicon substrate is first cleaned with acetone and secondly by oxygen plasma. This is to ensure the removal of photoresist and the residual passivation polymer deposited during etching (Fig. 3b). Following the cleaning steps, the etched wafer is sealed with a Borofloat glass wafer using an anodic bonding station at $40{ }^{\circ} \mathrm{C}$ and $1250 \mathrm{~V}$ for 45 minutes 


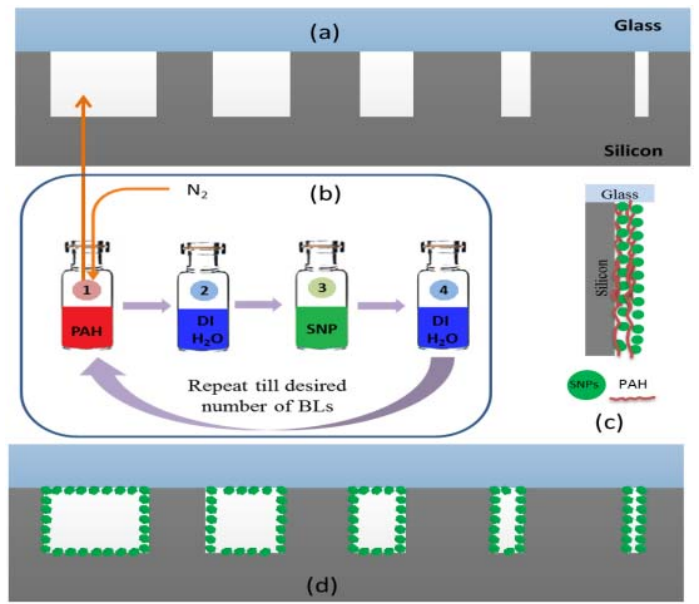

Fig. 3. Process flow (a) anisotropic etching followed by anodic bonding, (b) LbL coating till 10 bilayers (BLs) using SNPs, (c) two BLs shown inside channel, and (d) columns after calcination $\left(500{ }^{\circ} \mathrm{C}\right)$ and silane coupling.

(Fig. 3c). Subsequently, the bonded wafer is diced to expose two microfluidic ports of a number of serially connected devices for the newly developed stationary phase coating technique, as shown in Fig. 4.

\section{B. Stationary Phase Coating}

After the first dicing, the $25 \mathrm{~cm}$-long deactivated fused silica capillary tubes (outer diameter $220 \mu \mathrm{m}$, inner diameter $100 \mu \mathrm{m})$ are attached to the microfluidic ports with epoxy. Next, dry nitrogen and deionized (DI) water are passed through the devices to remove any dirt gathered during dicing. The complete details of layer-by-layer (LbL) coating of SNPs can be found in an earlier report [25]. Briefly, the $\mathrm{pH}$ values of polyallylamine hydrochloride (PAH) solution (Sigma-Aldrich) and SNPs suspension (Nissan Chemical) are first adjusted to $7.0( \pm 0.1)$ and $9.0( \pm 0.1)$, respectively, by adding $\mathrm{HCl}$ and $\mathrm{NaOH}$ solutions respectively. The LbL coating starts by alternately passing a positively-charged long-chain inert polymeric aqueous solution (PAH) and negatively-charged SNPs suspension through a number of serially connected multiple devices for three minutes to form one bilayer. The electrostatic attraction of each solute to the oppositely-charged surface provides strong, rapid adsorption of a nanoscale layer of the solute onto the surface. Each PAH and SNP coating step is followed by a 3 minute DI water rinsing step. This removes any excess coating material deposited during the prior step that is not strongly bound by electrostatic attraction. In the present work, this process is terminated after 10 bilayers of PAH and SNPs. Similar to our earlier work for very narrow channel-width $(20 \mu \mathrm{m})$ multicapillary columns [25], the original concentration of SNPs suspension is reduced to a third in order to achieve a uniform film thickness. At the end, the devices are thoroughly purged by passing DI water and dry nitrogen at low pressure for 15 minutes.

Next, the capillary tubes are removed and serially connected columns are diced into individual devices as shown in Fig. 4. Calcination is performed afterwards at $500{ }^{\circ} \mathrm{C}$ for 8 hours to remove the PAH layer and fuse SNPs together, resulting in a

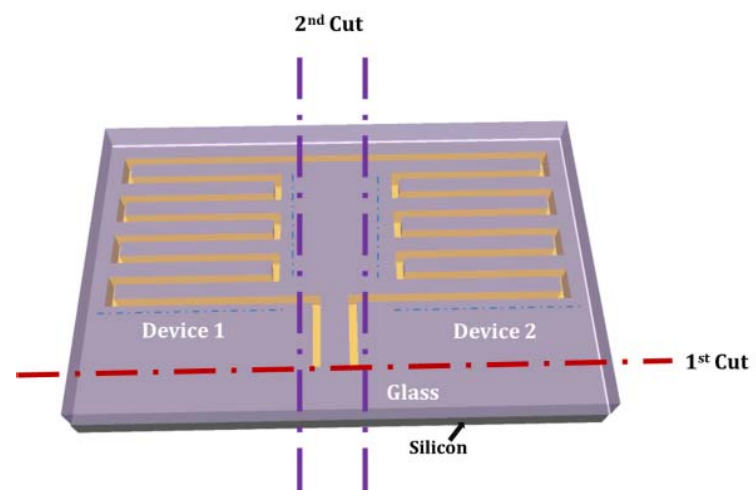

Fig. 4. Schematic representation of newly developed method for serial stationary phase coating utilizing LbL method to enable complete coverage of microchannel.
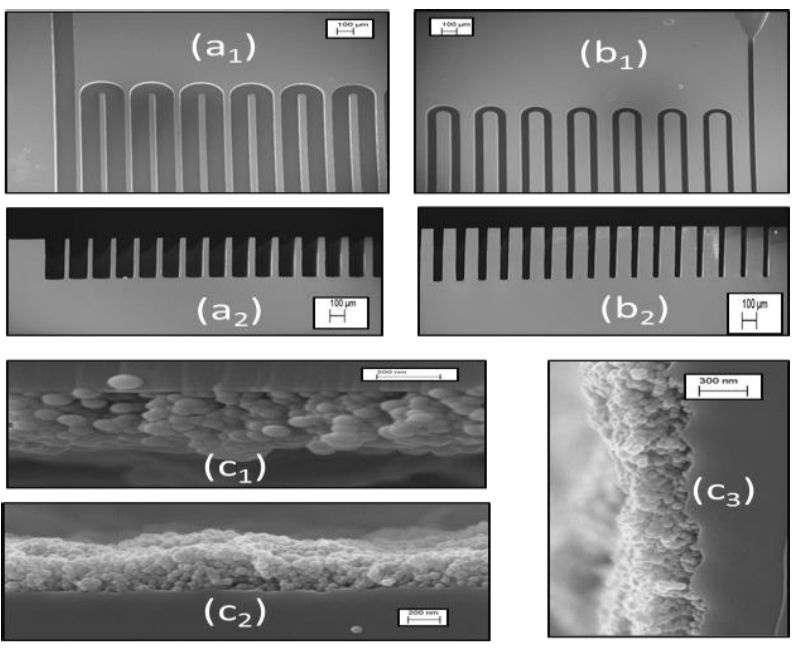

Fig. 5. Scanning electron micrographs of $\mu \mathrm{WMC}$ before bonding and SNPs coating (a-b), at $120 \mu \mathrm{m}$ inlet (a1) top view $\left(\mathrm{a}_{2}\right)$ cross sectional view and at $20 \mu \mathrm{m}$ inlet $\left(\mathrm{b}_{1}\right)$ top view $\left(\mathrm{b}_{2}\right)$ cross-sectional view, LbL SNPs coating after calcination and silane-coupling performed after bonding on $\left(\mathrm{c}_{1}\right)$ glass surface $\left(c_{2}\right)$ bottom of the channel and along $\left(c_{3}\right)$ side-wall.

stable and homogenous film. Following the calcination step, deactivated capillary tubes are fixed to the inlet and outlet ports of individual columns using epoxy. Before performing chromatographic separations, the surface of the SNPs is deactivated by filling each column with $10 \mathrm{mM}$ chlorodimethyl octadecyl silane (CDOS) diluted in toluene for 12 hours.

\section{Device Characterization}

The characterization of $\mu$ WMCs with a constant SNPs stationary phase film is performed using SEM (Fig. 5). First, it is verified from the SEM images (top and cross-sectional views) that only the column width is modulated (Fig. 5 a-b) without effectively changing the channel depth. It is pertinent to note that the effect of modulation in column depth on chromatographic separation could also be studied in the future and easily achieved by changing the DRIE etch parameters. Moreover, by employing the newly developed LbL SNPs coating after anodic bonding, a complete coverage of the microfluidic channel including the glass surface is realized (Fig. 5 C). This complete coverage of the separation channel 


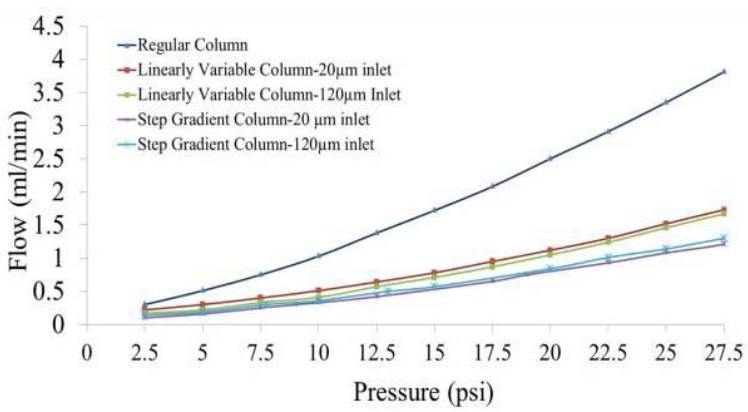

Fig. 6. Inlet pressure versus flow through different inlets of $\mu \mathrm{WMC}$ and regular column.

results in improving the analyte-stationary phase interaction. The film thickness measured at different locations (top, bottom and sidewalls) inside the modulating microfluidic channel show that 10 BLs of SNPs yield roughly a constant film thickness in the range of $400 \sim 500 \mathrm{~nm}$ (Fig. 5C). This is also consistent with our earlier reported LbL coating method [23] and demonstrates that the film thickness is proportional to the number of coating steps. The deviation in film thickness could be reduced further by utilizing nanoparticles with smaller average diameters for future studies.

\section{RESUlTS AND DisCUSSION}

\section{A. Experimental Setup}

The separation performance of the LVC, SGC and regular column is evaluated using a conventional GC oven (Agilent GC-7890A) equipped with an electronic pressure controller, a flame ionization detector (FID) and an autosampler (G-4513A). Both the injector and detector temperatures are maintained at $280{ }^{\circ} \mathrm{C}$ during $\mathrm{GC}$ testing. Ultra high purity nitrogen is used as a carrier gas for all experiments. Since nitrogen provides a higher theoretical plate number at a lower carrier gas velocity [30]. The chemicals used during the chromatographic testing are of HPLC standard and bought directly from Sigma-Aldrich. MEMS columns are attached to the inlet and detector ports using $25 \mathrm{~cm}$-long deactivated (uncoated) fused silica capillary tubes.

After silane-coupling each SNPs functionalized column is first purged with dry nitrogen for 15 minutes. This is followed by column maturing in a $\mathrm{GC}$ oven under a constant pressure of $10 \mathrm{psi}$ and an oven temperature of $140{ }^{\circ} \mathrm{C}$ until a flat baseline signal is observed. This step is necessary to driveoff contaminants from the column.

\section{B. Separation Results}

Since the newly developed LVC and SGC ( $\mu$ WMCs) configurations have microfluidic ports with different dimensions (i.e. $20 \mu \mathrm{m}$ and $120 \mu \mathrm{m}$ ), we can expect that the chromatographic response (retention times, flow rate and plate number) using each port as an inlet will be different. Therefore, both $\mu$ WMCs cannot be considered bidirectional unlike regular columns. So the presented chromatographic parameters are first analyzed utilizing both inlets of $\mu$ WMCs. As a first step, the flow rate through $\mu \mathrm{WMCs}$ and regular column is characterized against
TABLE I

Retention Times And Plate Numbers on $\mu$ WmCs And Regular Columns at 0.3 ML/Min Flow Rate Using N-NONANe AS a Probe

\begin{tabular}{|l|l|c|c|}
\hline \multicolumn{2}{|c|}{ Column Type } & $\begin{array}{c}\text { Retention } \\
\text { time } \\
(\mathrm{min})\end{array}$ & $\begin{array}{c}\text { Maximum } \\
\text { Plate } \\
\text { Number } \\
\left(\mathrm{N}_{\text {max }}\right)\end{array}$ \\
\hline Regular & 1.054 & 3522 \\
\hline $\begin{array}{l}\text { Linearly } \\
\text { Variable }\end{array}$ & $20 \mu \mathrm{m}$ Inlet & 1.041 & 5580 \\
\cline { 2 - 4 } & $120 \mu \mathrm{m}$ Inlet & 0.778 & 5496 \\
\hline $\begin{array}{l}\text { Step } \\
\text { Gradient }\end{array}$ & $20 \mu \mathrm{m}$ inlet & 0.457 & 6859 \\
\cline { 2 - 4 } & $120 \mu \mathrm{m}$ inlet & 0.643 & 5784 \\
\hline
\end{tabular}

the applied inlet pressure (Fig. 6) using a gas flow meter (ADM1000, Agilent Technologies). Due to a larger crosssectional area (along the column length), the regular column presents a higher flow rate, while the SGC shows the minimum flow rate with the smallest cross-sectional area. Following the flow rate characterization, the separation performance (plate number/meter) of the columns is evaluated according to [30]

$$
\mathbf{N}=\mathbf{5 . 5 4} *\left(\frac{\mathbf{t}_{\mathbf{r}}}{\mathbf{w}_{1 / 2}}\right)^{2}
$$

where $\mathrm{N}$ is the plate number, $t_{r}$ is the retention time and $\mathbf{w}_{\mathbf{1} / \mathbf{2}}$ is the peak width at half height.

From Table 1, it is clear that the inlet selection for $\mu \mathrm{WMCs}$ plays an important role with a significant difference in the plate numbers and retention times. It is clearly demonstrated that the SGC provides a higher plate number $(\mathrm{Nmax}=6859$ plates/meter) compared to the LVC (Nmax $=$ 5850 plates/meter). The higher plate numbers in the proposed $\mu \mathrm{WMCs}$ could be attributed to a gradual change in the width of the column and the stationary phase thickness. The sample molecules experience either a gradual reduction in solute-stationary phase interaction (using $120 \mu \mathrm{m}$ as an inlet port) along the column length or get separated fast at the start of the column within the narrower column region when the injector is connected to a $20 \mu \mathrm{m}$ column port. It has been shown (Table 1) that the later scenario provides an enhanced separation performance especially for the SGC. Furthermore, the LVC provides longer retention times than the SGC. Therefore, in order to achieve faster separations the SGC should be utilized but the LVC could provide a better separation resolution between different peaks. It can be further deduced that for both the $\mu \mathrm{WMCs}$ designs utilizing $20 \mu \mathrm{m}$ ports as inlets provide better separation efficiencies. Therefore, all the chromatographic results presented hereafter utilize $20 \mu \mathrm{m}$ ports as column inlets.

For $\mu$ WMCs the local plate height $(\overline{\mathbf{H E T P}})$ will vary with position (length) down the column due to a change in interaction between the stationary phase and the solute, as the relative linear velocities change. Since, $\overline{\text { HETP }}$ cannot be measured experimentally, the apparent plate height (HETP = 


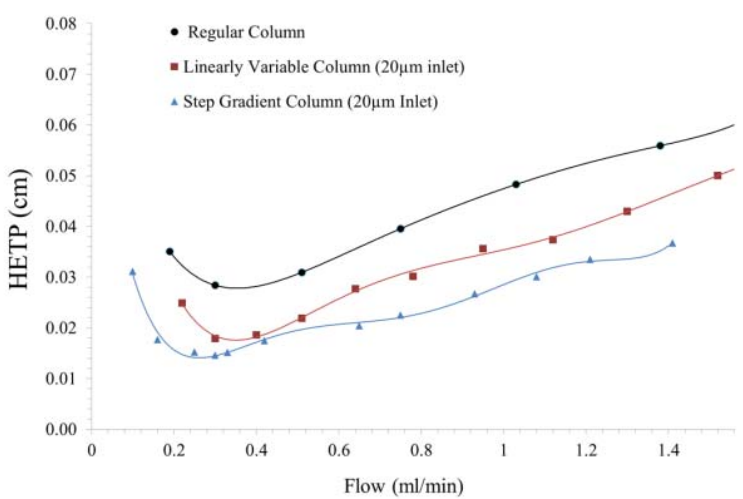

Fig. 7. Golay plots for different inlets of $\mu \mathrm{WMC}$ and regular column using nonane as a marker under isothermal conditions of $50{ }^{\circ} \mathrm{C}$ and $1 \mu \mathrm{L}$ sample injection.

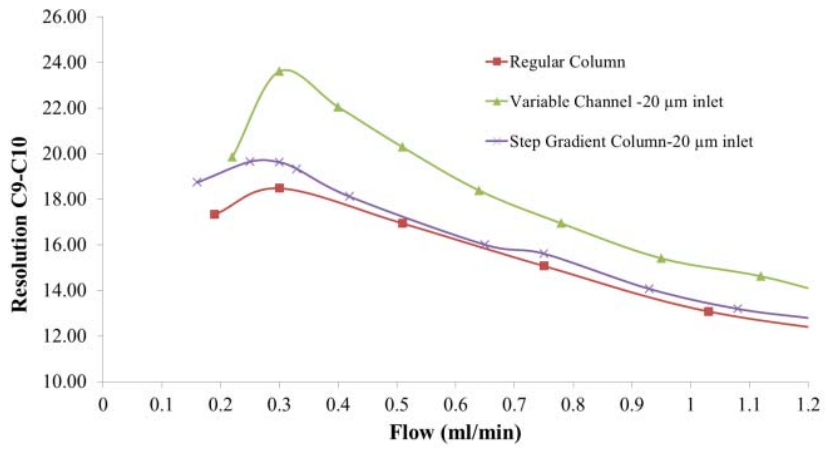

Fig. 8. Resolution between n-nonane and n-decane under isothermal conditions for different inlets of $\mu \mathrm{WMC}$ and regular column.

$\mathrm{L} / \mathrm{N}$ ) is calculated. From the Golay plots (Fig. 7), it is apparent that both LVC and SGC show superior performance compared to the regular columns $(\mathrm{Nmax}=3500$ plates $/ \mathrm{m})$ for all flow rates.

In order to optimize the GC analysis, apart from the retention time and plate number, the resolution should also be characterized. Resolution, a characteristic of the separation of two adjacent peaks, is calculated according to [30]

$$
\mathbf{R}=\mathbf{2} *\left\{\frac{\mathbf{t}_{\mathbf{r}_{\mathbf{b}}}-\mathbf{t}_{\mathbf{r}_{\mathbf{a}}}}{\mathbf{w}_{\mathbf{b}}+\mathbf{w}_{\mathbf{a}}}\right\}
$$

where $\boldsymbol{R}$ is the resolution, $\boldsymbol{t}_{\mathbf{r b}}$ and $\boldsymbol{t}_{\mathbf{r a}}$ are the retention times, $\boldsymbol{w}_{\boldsymbol{b}}$ and $\boldsymbol{w}_{\boldsymbol{a}}$ are peak widths at half heights of corresponding compounds a and $\mathrm{b}$, respectively.

Similar to HETP analysis, the LVC outperforms the fixed dimensional regular columns in terms of resolution between $\mathrm{n}$-nonane and $\mathrm{n}$-decane under isothermal conditions (Fig. 8). The effect of peak resolution is further demonstrated from the separation of a custom-made hydrocarbon mixture with nine compounds. It is clear from the separation results (Fig. 9) that under same flow rates the LVC is able to resolve all the nine compounds, while a regular microfabricated column is only able to resolve seven compounds in the test mixture. Moreover, it could also be concluded $\mu \mathrm{WMCs}$ are more suitable for the separation of compounds with lower boiling compounds.
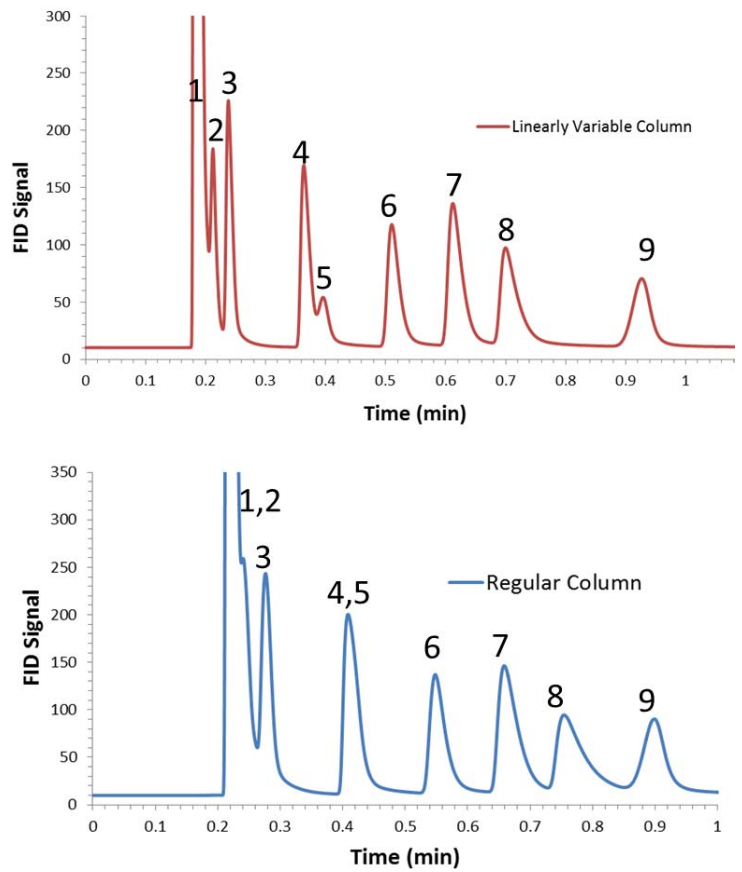

Fig. 9. GC separation results of a test mixture at $0.3 \mathrm{ml} / \mathrm{min}$ flow rate, $50{ }^{\circ} \mathrm{C}$ isothermal temperature and 100:1 split ratio. Compound identification in the order of elution: (1) dichloromethane-solvent, (2) n-hexane, (3) benzene, (4) toluene, (5) tetrachloroethylene, (6) chlorobenzene, (7) ethylbenzene, (8) p-xylene, (9) n-nonane.

Additionally, we note that the SGC is only able to separate eight compounds in the sample test mixture (not shown).

\section{CONCLUSION}

Two unidirectional $\mu \mathrm{WMCs}$ are introduced for the first time and provide better resolution, plate numbers, retention times and chromatographic separations than a regular fixed dimensional column. Multiple serially-connected columns are coated using LbL self-assembly of SNPs to enable a constant stationary phase film thickness. Moreover, the effects of modulation in column depth (controlled by micromachining parameters) and film thickness could also be studied as a future study. Similarly, the length of the $\mu$ WMCs could also be increased to study the effect of width modulation on the separation of lighter hydrocarbons.

\section{REFERENCES}

[1] H. Shakeel, W. Dong, R. Heflin, and M. Agah, "Width-modulated microgas chromatography separation columns with silica nanoparticles stationary phase," in Proc. IEEE Sensors, Nov. 2013, pp. 1-4.

[2] K. Reddy, Y. Guo, J. Liu, W. Lee, M. K. K. Oo, and X. Fan, "Rapid, sensitive, and multiplexed on-chip optical sensors for microgas chromatography," Lab Chip, vol. 12, no. 5, pp. 901-905, 2012.

[3] R. Haudebourg et al., "Temperature-programmed sputtered micromachined gas chromatography columns: An approach to fast separations in oilfield applications," Anal. Chem., vol. 85, no. 1, pp. 114-120, 2013.

[4] S. Narayanan, B. Alfeeli, and M. Agah, "Two-port static coated micro gas chromatography column with an embedded thermal conductivity detector," IEEE Sensors J., vol. 12, no. 6, pp. 1893-1900, Jun. 2012.

[5] S. Narayanan, G. Rice, and M. Agah, "A micro-discharge photoionization detector for micro-gas chromatography," Microchim. Acta, vol. 181, nos. 5-6, pp. 493-499, 2013.

[6] G. Serrano, D. Paul, S.-J. Kim, K. Kurabayashi, and E. T. Zellers, "Comprehensive two-dimensional gas chromatographic separations with a microfabricated thermal modulator," Anal. Chem., vol. 84, no. 16, pp. 6973-6980, 2012. 
[7] B. C. Kaanta, H. Chen, and X. Zhang, "A monolithically fabricated gas chromatography separation column with an integrated high sensitivity thermal conductivity detector," J. Micromech. Microeng., vol. 20, no. 5, p. $055016,2010$.

[8] L. K. Wright and E. T. Zellers, "A nanoparticle-coated chemiresistor array as a microscale gas chromatograph detector for explosive marker compounds: Flow rate and temperature effects," Analyst, vol. 138 no. 22, pp. 6860-6868, 2013.

[9] M. Akbar, S. Narayanan, M. Restaino, and M. Agah, "A purge and trap integrated microGC platform for chemical identification in aqueous samples," Analyst, vol. 139, pp. 3384-3392, 2014.

[10] M. Akbar et al., "Improved performance of micro-fabricated preconcentrators using silica nanoparticles as a surface template," J. Chromatography A, vol. 1322, pp. 1-7, Dec. 2013.

[11] M. Akbar and M. Agah, "A microfabricated propofol trap for breathbased anesthesia depth monitoring," J. Microelectromech. Syst., vol. 22 , no. 22, pp. 443-451, Apr. 2013.

[12] S. Zampolli et al., "Real-time monitoring of sub-ppb concentrations of aromatic volatiles with a MEMS-enabled miniaturized gaschromatograph,” Sens. Actuators B, Chem., vol. 141, no. 1, pp. 322-328, 2009.

[13] R. P. Manginell et al., "A monolithically-integrated $\mu \mathrm{GC}$ chemical sensor system," Sensors, vol. 11, no. 7, pp. 6517-6532, 2011.

[14] C.-J. Lu et al., "First-generation hybrid MEMS gas chromatograph," Lab Chip, vol. 5, no. 10, pp. 1123-1131, 2005.

[15] M. Agah, J. A. Potkay, G. Lambertus, R. Sacks, and K. D. Wise, "High-performance temperature-programmed microfabricated gas chromatography columns," J. Microelectromech. Syst., vol. 14, no. 5, pp. 1039-1050, Oct. 2005 .

[16] J. A. Potkay, G. R. Lambertus, R. D. Sacks, and K. D. Wise, "A lowpower pressure- and temperature-programmable micro gas chromatography column," J. Microelectromech. Syst., vol. 16, no. 5, pp. 1071-1079, Oct. 2007.

[17] S. Reidy, G. Lambertus, J. Reece, and R. Sacks, "High-performance, static-coated silicon microfabricated columns for gas chromatography," Anal. Chem., vol. 78, no. 8, pp. 2623-2630, 2006.

[18] A. D. Radadia, R. D. Morgan, R. I. Masel, and M. A. Shannon, "Partially buried microcolumns for micro gas analyzers," Anal. Chem., vol. 81, no. 9, pp. 3471-3477, 2009.

[19] M. Agah and K. D. Wise, "Low-mass PECVD oxynitride gas chromatographic columns," J. Microelectromech. Syst., vol. 16, no. 4, pp. 853-860, Aug. 2007.

[20] H. Shakeel and M. Agah, "Self-patterned gold-electroplated multicapillary gas separation columns with MPG stationary phases," J. Microelectromech. Syst., vol. 22, no. 1, pp. 62-70, Feb. 2013.

[21] H. Shakeel and M. Agah, "Semipacked separation columns with monolayer protected gold stationary phases for microgas chromatography," in Proc. IEEE Sensors, Oct. 2012, pp. 2007-2010.

[22] B. Alfeeli et al., "Interchannel mixing minimization in semi-packed micro gas chromatography columns," IEEE Sensors J., vol. 13, no. 11 , pp. 4312-4319, Nov. 2013.

[23] M. Stadermann et al., "Ultrafast gas chromatography on single-wall carbon nanotube stationary phases in microfabricated channels," Anal. Chem., vol. 78, no. 16, pp. 5639-5644, 2006.

[24] H. Shakeel, G. Rice, and M. Agah, "First reconfigurable MEMS separation columns for micro gas chromatography," in Proc. IEEE 25th Int. Conf. MEMS, Jan./Feb. 2012, pp. 823-826.

[25] D. Wang, H. Shakeel, J. Lovette, G. W. Rice, J. R. Heflin, and M. Agah, "Highly stable surface functionalization of microgas chromatography columns using layer-by-layer self-assembly of silica nanoparticles," Anal. Chem., vol. 85, no. 17, pp. 8135-8141, 2013.

[26] J. Vial et al., "Silica sputtering as a novel collective stationary phase deposition for microelectromechanical system gas chromatography column: Feasibility and first separations," J. Chromatography A, vol. 1218, no. 21, pp. 3262-3266, 2011.

[27] H. Purnell, Gas Chromatography. New York, NY, USA: Wiley, 1962.

[28] D. C. Locke and C. E. Meloan, "Gradient loaded columns in gas chromatography," Anal. Chem., vol. 36, no. 12, pp. 2234-2243, 1964

[29] G. E. Spangler, "Relationships for modeling the performance of rectangular gas chromatographic columns," J. Microcolumn Separat., vol. 13, no. 7, pp. 285-292, 2001.

[30] H. M. McNair and J. M. Miller, Basic Gas Chromatography. New York, NY, USA: Wiley, 2011.

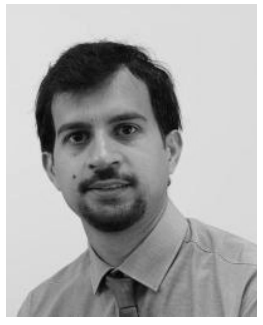

Hamza Shakeel received the B.S. degree in electronic engineering from the Ghulam Ishaq Khan Institute of Engineering Sciences and Technology, Topi, Pakistan, in 2004, and the M.S. degree in electrical engineering from the University of Maryland, College Park, MD, USA, in 2010. He is currently pursuing the Ph.D. degree at the Virginia Tech MEMS Laboratory, Bradley Department of Electrical and Computer Engineering, Blacksburg, VA, USA. His research interests include micro and nanofabrication techniques, chemical sensors, and application of nanomaterials for gas sensing applications.

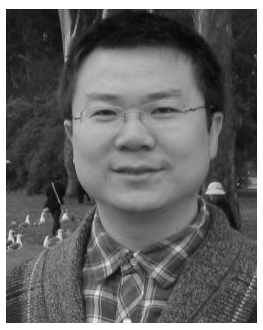

Dong Wang received the B.S. and M.S. degrees in applied physics from the University of Science and Technology of China, Hefei, China, in 2004 and 2007, respectively. He is currently pursuing the Ph.D. degree in experimental condensed matter physics at the Virginia Polytechnic Institute and State University, Blacksburg, VA, USA. His research interests include nanostructured thin-film coatings and their application on ion-conductive polymer electromechanical bending actuators/sensors and microgas chromatography devices.

James R. Heflin received the Ph.D. degree in physics from the University of Pennsylvania, Philadelphia, PA, USA, in 1990. He is a Professor of Physics and Associate Director of the Center for Self-Assembled Nanostructures and Devices with the Virginia Polytechnic Institute and State University (Virginia Tech), Blacksburg, VA, USA, where he has been a Faculty Member since 1992. His research focuses on self-assembly of organic optoelectronic materials and devices, an area in which he holds three patents, and has authored 130 papers. He is the Co-Editor of the textbook Introduction to Nanoscale Science and Technology and an Associate Editor of International Journal of Nanoscience, and is leading the development of the Bachelor of Science in Nanoscience degree at Virginia Tech. He is also the Co-Founder and Chief Technology Officer of Virginia nanoTech LLC, Blacksburg.

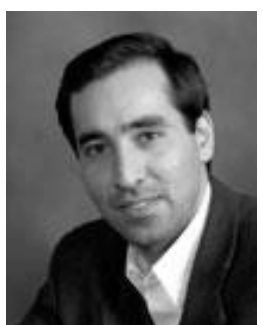

Masoud Agah (SM'09) received the B.S. and M.S. degrees in electrical engineering from the Sharif University of Technology, Tehran, Iran, in 1996 and 1998, respectively, and the Ph.D. degree from the University of Michigan, Ann Arbor, MI, USA, in 2005. He began the undergraduate studies in 1992 after being awarded by the President of Iran for achieving the first rank in the Nationwide Iranian University Entrance Examination. During his studies, he received numerous awards, including the Iranian Exemplary Graduate Student Honor Award by the President Khatami in 1998. In 2000, he joined the NSF Center for Wireless Integrated MicroSystems (WIMS ERC), University of Michigan, where he developed MEMS-based gas chromatography columns for environmental monitoring applications. He joined the faculty of the Virginia Polytechnic Institute and State University (Virginia Tech), Blacksburg, VA, USA, in 2005, where he is currently an Associate Professor with the Bradley Department of Electrical and Computer Engineering, with a courtesy appointment at the Department of Mechanical Engineering. He is also a Core Faculty Member of the Wake Forest School of Biomedical Engineering and Sciences at Virginia Tech. He established the VT MEMS Laboratory, in 2005, and has focused his research on environmental and biomedical applications of MEMS and nanotechnology. He is a member of the American Society for Mechanical Engineers. 